\title{
Antioxidant and Pasting Properties of Oat $\beta$-Glucan Hydrocolloids
}

\author{
George E. Inglett*, Diejun Chen \\ USDA, Agricultural Research Service, National Center for Agricultural Utilization Research, Functional Foods Research Unit 1815 \\ N, Peoria, USA. \\ Email: *George.Inglett@ars.usda.gov
}

Received March $2^{\text {nd }}, 2012$; revised May $2^{\text {nd }}, 2012$; accepted May $11^{\text {th }}, 2012$

\begin{abstract}
Four oat $\beta$-glucan enriched hydrocolloids (Nutrim10, C-Trim20, C-Trim30, C-Trim50), oat bran concentrate (OBC), and $\beta$-Glucan95 were investigated for antioxidant and pasting properties. C-Trim 30 had the highest soluble phenolic content, followed by C-Trim20. The trend of antioxidant activity was similar with that of phenolic contents. The phenolic content of the extracts increased with increasing temperatures. The highest content of soluble phenolic compounds was found at temperatures up to $100^{\circ} \mathrm{C}$ for most samples regardless of solvent. Water extracts had significantly higher phenolic contents than extracts from $50 \%$ ethanol at $100^{\circ} \mathrm{C}$ for all samples with the exception of C-Trim 30 . However, the effect of temperature and solvent concentrations was not as apparent for antioxidant activity as that observed for phenolic content. In general, the differences in three different solvents were not as apparent. Significantly higher water holding capacities were found for C-Trim30 and C-Trim50 than the other samples while $\beta$-Glucan 95 had substantially the highest paste viscosity followed by C-Trim50 and C-Trim 30 .
\end{abstract}

Keywords: Oat; $\beta$-Glucan; Hydrocolloids; Pasting Properties; Antioxidant Activity

\section{Introduction}

Oat bran has been widely reported to provide a vast range of human health benefits such as serum cholesterol lowering [1], reduced coronary heart disease [2], reduced symptoms of diabetes [3], reduced blood pressure [4], cancer prevention [5], and obesity [6]. A primary component of oat bran implicated for these health benefits is $\beta$-glucan; however, oat phenolic and other antioxidant compounds also provide health benefits as demonstrated for barley [7].

Oat bran hydrocolloids were prepared from oat bran concentrate $(\mathrm{OBC})$ that contains natural dietary fibers with about $12 \%$ as $\beta$-glucan. Processed OBC produced oat bran hydrocolloids contain about $15 \%-50 \% \beta$-glucan depending on procedures used. Several oat bran hydrocolloids with enriched $\beta$-glucan were developed and patented for healthy and nutritional food products by the United States Department of Agriculture in Peoria, IL [8]. Oat bran hydrocolloids, Nutrim and C-Trim, were produced from $\mathrm{OBC}$ that was subjected to mechanical shear and steam jet-cooking procedures. $\mathrm{OBC}$, Nutrim and $\mathrm{C}$ Trim products containing $12-50 \beta$-glucan have beneficial effects on coronary heart disease prevention by the reduction of serum cholesterol and postprandial serum

${ }^{*}$ Corresponding author. glucose levels [9].

The antioxidant capacity of oats is contributed by the presence of tocopherols, tocotrienols, phytic acid, flavonoids, and non-flavonoid phenolic compounds including avenanthramides [10]. Oat antioxidants were reported to inhibit low-density lipoprotein oxidation and promote scavenging of reactive oxygen [1]. Avenanthramides have been implicated in inhibiting artherosclerosis [11]. Lignin and $\beta$-glucan of oat together exhibited cholesterol-lowering effect contributed to binding with bile acids [12]. The highest phenolic contents and antioxidant activities were extracted from defatted and air-classified $\mathrm{OBC}$ using $50 \%$ ethanol at $150^{\circ} \mathrm{C}$ with microwave-irradiation [13]. The total phenolic content in cereal extracts was reported in the order: buckwheat $<$ wheat bran $<$ oat expressed as gallic acid equivalent [14]. Most whole grain phenolics are in the bound form, such as corn (85\%), wheat $(76 \%)$, and oats $(75 \%)$, whereas bound ferulic acid was significantly higher than free and soluble conjugated ferulic acid in corn, wheat, oats, and rice [5].

Various solvents have been evaluated for their potential to extract phenolic compounds and other components contributing to antioxidant activity. Methanol extraction of milled oat groats yielded higher total phenolics than isopropanol [15]. The highest antioxidant activity was found from methanol extracts among eight solvent com- 
binations involving ether, diethyl ether, petroleum ether, chloroform, dichloroethane and methanol [16]. The most effective solvent for extracting phenolic antioxidants from wheat bran was $50 \%$ acetone by comparison to $70 \%$ methanol or ethanol, and 100\% ethanol [17]. An 80\% methanol extraction of whole oats gave substantially higher total phenolic compounds and exhibited higher antioxidant capacity than water extracts [18] whereas $80 \%$ methanol or ethanol was found to be efficient for extracting phenolic compounds from barley $[19,20]$.

Recently, food products containing oat $\beta$-glucan hydrocolloids have gained considerable interest by consumers for their health benefits. Oat $\beta$-glucan hydrocolloids have numerous potential functional food applications as a source of $\beta$-glucan as well as a fat substitute for making reduced calorie food products. It was reported that a $5 \%$ dispersion of Nutrim 10 had the same consistency as coconut cream in several Thai desserts [21]. In addition, fat in muffins and frozen desserts was replaced with Nutrim10, and the effect on their flavor and texture was evaluated [22]. A recent study showed that shortening in cakes could be substituted up to $40 \%$ by Nutrim 10 without loss of cake quality [23]. Also, rheological and physical evaluation of jet-cooked oat bran has been studied in low calorie cookies with a successful replacement of $20 \%$ shortening by oat $\beta$-glucan hydrocolloids [24].

Although studies of oat bran hydrocolloids in food applications and rheological properties were conducted, information on phenolic contents and antioxidant activities of oat $\beta$-glucan hydrocolloids has been limited. Also, the relationship between $\beta$-glucan contents and phenolic contents along with antioxidant activities needed more clarification. More fundamental studies on oat $\beta$-glucan hydrocolloids were needed on paste viscosity since it has a great influence on final product quality. Therefore, this study was conducted to investigate the effectiveness of temperature and solvents on phenolic and other antioxidant compounds from $\mathrm{OBC}$ and oat $\beta$-glucan hydrocolloids along with their water absorption and paste viscosities. These results could be valuable for developing and processing new functional foods having desirable texture and health benefits.

\section{Materials and Methods}

\subsection{Samples}

Oat bran concentrate was supplied by Quaker Oat. Nutrim10, C-Ttrim20, C-Trim30, C-Trim50 were obtained from VDF FutureCeuticals (Momence, IL). Beta-Glucan $95 \%$ is available from Megazyme International Ireland Ltd. (Wicklow, Ireland).

\subsection{Processing Procedure}

Oat bran concentrate: by sieving OBC (Lot 18608408);
Nutrim10: oat bran concentrate was jet cooked, solids were removed by sieve, and liquid was drum-dried (Lot $35503475 \mathrm{~N} 170$ );

C-Trim20: starch was removed from oat bran concentrate before jet-cooking, solids were removed by sieve, and liquid was drum-dried (Lot 1240000);

C-Trim30: starch was removed from oat bran concentrate before jet-cooking, solids were removed by centrifugation, and supernatant was drum-dried (Lot PP6JC-SL-CL-DD-2);

C-Trim50: starch was removed from oat bran concentrate before jet-cooking, solids were removed by centrifugation, and the solids precipitated from supernatant by ethanol prior to freeze-drying (Lot PP6-JC-SL2-CS1DS-FD2).

The $\beta$-glucan contents from FIA and Enzyme methods and molecular weight at peak were list in Table 1 [25].

\subsection{Sample Extraction}

Sample $(0.1 \mathrm{~g})$ was suspended in solvent and then heated in a water bath at $23^{\circ} \mathrm{C}, 50^{\circ} \mathrm{C}$ and $100^{\circ} \mathrm{C}$ for $15 \mathrm{~min}$ with $10 \mathrm{ml}$ of water or $50 \%$ ethanol respectively, mixing by Vortex in every five min using a vortex machine. For the solvent study, the extraction method was modified based upon a previous method [26,27]. Samples $(0.5 \pm 0.01 \mathrm{~g})$ were extracted with $10 \mathrm{ml}$ of $70 \%$ acetone, $70 \%$ ethanol, $70 \%$ methanol (solvent: water, $70 / 30, \mathrm{v} / \mathrm{v}$ ) in duplicate , respectively, for $2 \mathrm{~h}$ at room temperature in a water bath having a shaker.

\subsection{Total Phenolic Content}

Phenolic content was determined by the Folin-Ciocalteau colorimetric method as described previously with minor modifications [28,29]. To $100 \mu \mathrm{L}$ of extract, $7.9 \mathrm{~mL}$ of deionized water and $0.5 \mathrm{~mL}$ of Folin-Ciocalteau reagent (F9252, Sigma Aldrich, St Louis, MO) were added, mixed on a vortex mixer, and $1.5 \mathrm{~mL}$ of $1.85 \mathrm{M} \mathrm{Na}_{2} \mathrm{CO}_{3}$ was added after $15 \mathrm{~min}$. Absorbance of samples was measured at $765 \mathrm{~nm}$ after $2 \mathrm{~h}$. Gallic acid was used as a standard, and the results were expressed as mg of gallic acid equivalents per $g$ on dry base (d.b.). Each sample was analyzed in triplicate.

Table 1. Processing condition, $\beta$-glucan content, and molecular weight at peak [25].

\begin{tabular}{ccccc}
\hline \multirow{2}{*}{ Sample ID } & \multirow{2}{*}{ Nominal } & \multicolumn{3}{c}{$\beta$-glucan content (\%) } \\
\cline { 3 - 4 } & & FIA method & Enzyme method \\
\hline OBC & 15 & 12.4 & 12.0 & $1.5 \times 10^{6}$ \\
Nutrim10 & 10 & 16.0 & 15.5 & $3.0 \times 10^{5}$ \\
C-Trim20 & 20 & 25.4 & 27.7 & $2.6 \times 10^{5}$ \\
C-Ttrim30 & 30 & 35.0 & 36.0 & $2.7 \times 10^{5}$ \\
C-Ttrim50 & 50 & 44.6 & 46.0 & $4.4 \times 10^{5}$ \\
\hline
\end{tabular}




\subsection{Antioxidant Activity}

Antioxidant activity procedure was modified based on a previous method by reacting $0.5 \mathrm{~mL}$ of extract with 0.5 $\mathrm{mL}$ of $200 \mu \mathrm{M}$ 2,2-diphenyl-1-picryl-hydrazyl (DPPH) in a cuvette for $40 \mathrm{~min}$ in dark followed by converting the cuvettes after adding reagent and prior to reading the absorbance at $515 \mathrm{~nm}$ [30]. Results were expressed as umol of 6-hydroxy-2,5,7,8-tetramethylchroman-2-carboxylic acid (Trolox) equivalents per g (d.b.). Each sample was analyzed in triplicate.

\subsection{Water Holding Capacity}

The water-holding capacity was determined according to a modified procedure from an earlier study [31]. Samples (2 g) were mixed with $25 \mathrm{ml}$ of deionized water, mixed using a vortex to make a suspension, held for $2 \mathrm{~h}$, and followed by centrifugation at $1590 \mathrm{~g}$ for $15 \mathrm{~min}$. The supernatant was decanted and the residue weight measured. Each treatment was replicated twice. Water-holding capacity was calculated by the following equation:

Water holding capacity (\%)

$=\frac{\text { Sample weight after centrifugation }- \text { dry sample weight }}{\text { dry sample weight }}$

$\times 100$

\subsection{RVA Measurements}

Pasting properties of oat $\beta$-glucan hydrocolloids were measured using a Rapid Visco Analyzer (RVA-4, Perten Scientific, Springfield, IL). Samples (2.24 g d.b.) were made up to a total weight of $28 \mathrm{~g}$ with deionized water in a RVA canister $(8 \%$ solids, w/w). Suspensions were equilibrated at $50^{\circ} \mathrm{C}$ for $1 \mathrm{~min}$, heated to $95^{\circ} \mathrm{C}$ at a rate of $6.0^{\circ} \mathrm{C} / \mathrm{min}$, maintained at $95^{\circ} \mathrm{C}$ for $5 \mathrm{~min}$, and cooled to $50^{\circ} \mathrm{C}$ at rate of $6.0^{\circ} \mathrm{C} / \mathrm{min}$ and held at $50^{\circ} \mathrm{C}$ for $2 \mathrm{~min}$. For all test measurements, a constant paddle rotating speed (160 rpm) was used throughout the entire analysis except for $920 \mathrm{rpm}$ in the first $10 \mathrm{~s}$ to disperse sample. Each sample was analyzed in duplicate.

\subsection{Statistical Analysis}

Standard deviation is reported for all measurements in tables and error bars in figures.

Data were analyzed using SAS software using analysis of variance with Tukey's multiple comparison adjustment to determine significant differences $(p<0.05)$ between treatments [32].

\section{Results and Discussion}

\subsection{Phenolic Contents and Antioxidant Activities}

3.1.1. Differences between Samples

C-Trim30, followed by C-Trim20, appeared to have the highest soluble phenolic content using the same extraction conditions for all samples tested (Table 2). OBC and Nutrim 10 had relatively lower $\beta$-glucan content $(12.0 \%$ $\& 15.5 \%)$ than C-Trim30 (36.0\%) and C-Trim50 (46.0\%, Table 1) by enzyme method. The total soluble phenolic contents in $\mathrm{OBC}(5.30 \mathrm{mg} / \mathrm{g}, 6.01 \mathrm{mg} / \mathrm{g})$ and Nutrim 10 $(5.80 \mathrm{mg} / \mathrm{g}, 6.06 \mathrm{mg} / \mathrm{g})$ at room temperature were lower than C-Trim 30 and C-Trim20 but comparable with that of C-Trim50 (5.74 mg/g, $5.46 \mathrm{mg} / \mathrm{g}$ ) as showed in Table 2. The results suggest that the phenolic compounds were probably not related to $\beta$-glucan contents.

A similar trend was observed for antioxidant activity as that of phenolic contents in this study. C-Trim30 had the highest antioxidant activity, followed by C-Trim 20 and others. C-Trim50 and Nutrim10 had similar antioxidant activity, but comparatively lower antioxidant activity than C-Trim 30 and C-Trim20. Interestedly, OBC had a higher phenolic content than $\mathrm{C}$-Trim50. Perhaps these results may be contributed by some components of $\mathrm{OBC}$ since some oat bran cell walls were excluded from $\mathrm{C}$ Trim50 by centrifugation and alcohol precipitation during processing. Studies have reported that the phenolic compounds are primarily bound to cell walls for most cereal grains [5]. In addition, OBC did not undergo hydrothermal-shearing, so the antioxidant activities could be reduced by oxidation during processing of C-Trim50. Antioxidants could be lost during oil processing procedure [33]. Furthermore, severe hydrolysis in extraction may alter structures that no longer represent the real antioxidant activity. Also, the measurement of the true "total antioxidant activity" is still a challenge because of the diverse polarity of antioxidants and the fact that most of them are covalently bound to an insoluble matrix [34]. Total phenolic content has been reported to be higher in oat hulls than groats [35] but total antioxidant capacity was higher in oat groats [36]. Perhaps these prior references may partly explain the low antioxidant activities in oat hydrocolloids since they are produced from processed oat bran.

\subsubsection{Effect of Extraction Temperature}

The phenolic contents of extracts increased with increasing temperatures for both water and $50 \%$ ethanol extracts (Table 2). The extraction temperature up to $100^{\circ} \mathrm{C}$ resulted in the highest solubilized phenolic compounds for most samples regardless of solvent. Overall, no significant differences were found in total phenolics between $23^{\circ} \mathrm{C}$ and $50^{\circ} \mathrm{C}$, except for C-Trim 20 extracted by $50 \%$ ethanol. Increase in phenolic contents at elevated temperatures using water bath and microwave have been previously reported for oat and buckwheat products [13,37]. Extrusion cooking of oats at $200^{\circ} \mathrm{C}$ increased vanillic, ferulic and coumaric acids but decreased sinapic acid and unaltered syringic acid [18]. Autoclaving oats resulted in en- 
Table 2. Phenolic contents and antioxidant activities of oat $\beta$-glucan hydrocolloids at different temperatures.

\begin{tabular}{|c|c|c|c|c|c|}
\hline & \multirow{2}{*}{${ }^{\circ} \mathrm{C}$} & \multicolumn{2}{|c|}{ Phenolic Content } & \multicolumn{2}{|c|}{ Antioxidant Activity } \\
\hline & & Water & Ethanol (50\%) & Water & Ethanol (50\%) \\
\hline \multirow{3}{*}{$\mathrm{OBC}$} & 23 & $5.30 \pm 0.01^{\text {B.d }}$ & $6.01 \pm 0.14^{\text {A.gf }}$ & $3.95 \pm 0.17^{\mathrm{A} . \mathrm{cbd}}$ & $4.29 \pm 0.21^{\mathrm{A} . \mathrm{d}}$ \\
\hline & 50 & $5.66 \pm 0.06^{\text {B.d }}$ & $6.20 \pm 0.12^{\mathrm{A} . \mathrm{f}}$ & $4.16 \pm 0.07^{\mathrm{B} . b c}$ & $4.73 \pm 0.01^{\text {A.cd }}$ \\
\hline & 100 & $8.27 \pm 0.11^{\text {A.c }}$ & $7.56 \pm 0.03^{\text {B.d }}$ & $4.28 \pm 0.32^{\text {B.b }}$ & $5.68 \pm 0.19^{\text {A.b }}$ \\
\hline \multirow{3}{*}{ Nutrim10 } & 23 & $5.80 \pm 0.13^{\text {A.d }}$ & $6.06 \pm 0.09^{\text {A.gf }}$ & $2.63 \pm 0.06^{\text {A.e }}$ & $2.73 \pm 0.20^{\text {A.e }}$ \\
\hline & 50 & $5.81 \pm 0.03^{\mathrm{B.d}}$ & $6.06 \pm 0.02^{\text {A.gf }}$ & $2.70 \pm 0.23^{\text {A.e }}$ & $2.65 \pm 0.15^{\text {A.e }}$ \\
\hline & 100 & $8.49 \pm 0.01^{\text {A.c }}$ & $6.65 \pm 0.10^{\text {B.e }}$ & $2.90 \pm 0.11^{\text {A.ed }}$ & $2.89 \pm 0.20^{\text {A.e }}$ \\
\hline \multirow{3}{*}{ C-Trim 20} & 23 & $7.87 \pm 0.16^{\text {A.c }}$ & $7.72 \pm 0.17^{\mathrm{A} . \mathrm{d}}$ & $5.06 \pm 0.04^{\mathrm{A} . \mathrm{b}}$ & $4.69 \pm 0.05^{\text {B.cd }}$ \\
\hline & 50 & $8.17 \pm 0.14^{\mathrm{A} . \mathrm{c}}$ & $8.23 \pm 0.04^{\mathrm{A} . c}$ & $4.94 \pm 0.36^{\text {A.b }}$ & $4.54 \pm 0.18^{\mathrm{A.d}}$ \\
\hline & 100 & $11.59 \pm 0.13^{\text {A.a }}$ & $9.70 \pm 0.05^{\text {B.b }}$ & $4.96 \pm 0.04^{\mathrm{A} . \mathrm{b}}$ & $5.24 \pm 0.25^{\mathrm{A} . c b}$ \\
\hline \multirow{3}{*}{ C-Trim30 } & 23 & $10.39 \pm 0.33^{\text {A.ab }}$ & $9.55 \pm 0.04^{\mathrm{A} . \mathrm{b}}$ & $6.57 \pm .21^{\text {A.a }}$ & $6.80 \pm 0.08^{\text {A.a }}$ \\
\hline & 50 & $10.85 \pm 0.11^{\text {A.a }}$ & $10.63 \pm 0.04^{\text {A.a }}$ & $6.57 \pm 0.06^{\text {B.a }}$ & $7.18 \pm 0.13^{\text {A.a }}$ \\
\hline & 100 & $11.53 \pm 0.28^{\text {A.a }}$ & $10.97 \pm 0.22^{\text {A.a }}$ & $6.59 \pm 0.01^{\text {B.a }}$ & $6.89 \pm 0.08^{\text {A.a }}$ \\
\hline \multirow{3}{*}{ C-Trim50 } & 23 & $5.74 \pm 0.06^{\mathrm{A} . \mathrm{d}}$ & $5.46 \pm 0.07^{\text {B.h }}$ & $1.75 \pm 0.06^{\text {A.e }}$ & $1.73 \pm 0.01^{\text {A.f }}$ \\
\hline & 50 & $8.25 \pm 0.04^{\mathrm{A} . \mathrm{c}}$ & $5.59 \pm 0.06^{\text {B.h }}$ & $2.95 \pm 0.54^{\mathrm{A} . \mathrm{cde}}$ & $1.76 \pm 0.05^{\text {A.f }}$ \\
\hline & 100 & $9.23 \pm 0.08^{\text {A.cb }}$ & $5.72 \pm 0.13^{\text {B.gh }}$ & $2.96 \pm 0.04^{\text {A.cde }}$ & $2.06 \pm 0.08^{\text {B.f }}$ \\
\hline
\end{tabular}

Samples $(0.1 \mathrm{~g})$ were extracted with $10 \mathrm{ml}$ of corresponding solvents; Values of phenol contents are reported in mg gallic acid equivalents/g sample; values of antioxidant activities are reported in $\mu \mathrm{mol}$ Trolox equivalents/g sample; The different capital-letter superscripts within row for respect test, or different lowerletter superscripts within column indicate the significance $(p<0.05)$.

hanced $\alpha$ - and $\beta$-tocopherol, $\alpha$ - and $\beta$-tocotrienol, vanillin, ferulic and $p$-coumaric acid contents, but decreased avenanthramides [36]. The study of microwave irradiation on the stability of over 20 phenolic compounds found that all were stable at least for up to $20 \mathrm{~min}$ at $100^{\circ} \mathrm{C}$ [38]. These studies indicated that phenolic compounds are fairly stable, and also suggested that high temperature may disrupt the cellular structure and liberate more phenolic compounds.

In contrast, the effect of temperature on antioxidant activity was not as apparent as that observed for phenolic content (Table 2). Although the slightly increasing trends for antioxidant activities were observed for both water and $50 \%$ ethanol; a significant increase was only found for the antioxidant activities of the $50 \%$ ethanol extracts when temperature increased from $50^{\circ} \mathrm{C}$ to $100^{\circ} \mathrm{C}$ for OBC (Table 2). An earlier study confirmed that rutin and quercetin, two of the most common polyphenolic antioxidants in buckwheat, were unstable in phosphate buffer at $97^{\circ} \mathrm{C}$ in the presence of transition metal ions [39]. Moreover, high temperature may effectively solubilizes more phenolic compounds with no antioxidant activity, such as vitexin and isovitexin [40].

\subsubsection{Effect of Ethanol Concentrations}

Water and $50 \%$ ethanol were chosen for an optimum extraction study. One hundred percent ethanol was not included in this study because $100 \%$ ethanol extracts revealed that it gave the lowest phenolic content compared to water and $50 \%$ ethanol at all temperatures of the heating method in a previous study [37]. Water tended to produce extracts with more total phenolic contents than $50 \%$ ethanol for C-Trim50 (Table 2) at all temperatures and comparable phenolic content with $50 \%$ ethanol for Nutrim10, C-Ttrim20, and C-Trim30. Water extracts had significantly higher phenolic content than extracts with $50 \%$ ethanol at $100^{\circ} \mathrm{C}$ for all samples with the exception of C-Trim30 (Table 2). These studies were in agreement with a prior study that $50 \%$ ethanol extracted substantially more phenolic compounds than water and $100 \%$ ethanol when using microwave irradiated or heated with water bath at all temperatures [37].

With respect to antioxidant activity, however, no consistent advantage of $50 \%$ aqueous ethanol over water was observed (Table 2) as antioxidant activities in water extracts were similar to that from $50 \%$ aqueous ethanol. These studies were in agreement with a previous study on extracts from distillers' dried grain [41].

\subsubsection{Effect of Solvent Types}

The methanol extract showed the highest antioxidant activity coefficient while the acetone extract showed the 
highest total phenolics of catechin equivalents and the highest scavenging activity by the DPPH method [42]. Also, methanol was reported to extract lower molecular weight phenolic compounds than using hexane or aqueous acetone [43]. Another study on wheat suggested that $50 \%$ acetone would provide extracts with considerably higher antioxidant activity [17]. However, the differences in phenolic contents among the three solvent types were not very dramatic in this study. Using both $80 \%$ ethanol and $80 \%$ methanol extractions resulted in significantly higher soluble phenolic compounds than using $80 \%$ acetone for C-Trim30 (Table 3). Also, 80\% ethanol extracted significantly higher soluble phenolic compounds than $80 \%$ methanol for $\mathrm{OBC}$ and $80 \%$ acetone for CTrim20. No significant differences were found in this study for Nutrim10, C-Trim50 and $\beta$-glucan95 regardless of solvent types. Significantly higher antioxidant activities were found in the extracts using $80 \%$ ethanol and methanol compared to $80 \%$ acetone for the corresponding samples with the exclusion of C-Trim 30 using $80 \%$ ethanol (Table 4). It implies that the antioxidants from oat $\beta$-glucan hydrocolloids probably are more stable in ethanol and methanol than acetone. No detectable antioxidant activities were found in $\beta$-Glucan95 for all three solvents used.

\subsubsection{The Comparison of Gallic Acid and Ferulic Acid as Standards for Phenolic Analysis}

Ferulic acid plays a significant role in the plant cell walls because it forms bonding between polysaccharides and proteins [44]. Ferulic acid is a well known antioxidant with potential for food and medical applications [45]. Gallic acid is commonly used for testing phenolic content. This study was the first to report using ferulic acid as standard to determine phenolic content in corn bran. The statistical significant differences were found for most samples using $80 \%$ ethanol and $80 \%$ methanol between the results using gallic acid or ferulic acid as standard (Table 5). Overall, the results using gallic acid as standard were higher than the results using ferulic acid as standard. The results from this study provided an alternative choice for using ferulic acid as standard to test phenolic content.

\subsubsection{Effect of Sample and Solvent Ratio}

The effect of sample and solvent ratios on phenolic contents was also observed in this study. For example, phenolic content for C-Trim30 was $10.39 \mathrm{mg} / \mathrm{g}$ and 9.55 $\mathrm{mg} / \mathrm{g}$ using water or ethanol, respectively (Table 2). In contrast, phenolic content for the same sample was 5.78, $6.31,6.26 \mathrm{mg} / \mathrm{g}$ using $80 \%$ acetone, ethanol, methanol respectively. Different solvent types, such as water, $50 \%$ of ethanol, $80 \%$ of acetone, $80 \%$ of ethanol, and $80 \%$ of methanol made some differences. Sample and solvent
Table 3. Phenolic contents of oat $\boldsymbol{\beta}$-glucan hydrocolloids.

\begin{tabular}{cccc}
\hline & $\begin{array}{c}\text { Acetone }(80 \%) \\
\mathrm{mg} / \mathrm{g}\end{array}$ & $\begin{array}{c}\text { Ethanol (80\%) } \\
\mathrm{mg} / \mathrm{g}\end{array}$ & $\begin{array}{c}\text { Methanol (80\%) } \\
\mathrm{mg} / \mathrm{g}\end{array}$ \\
\hline OBC & $2.29 \pm 0.09 \mathrm{ef}$ & $2.25 \pm 0.03 \mathrm{ef}$ & $1.78 \pm 0.02 \mathrm{~g}$ \\
Nutrim10 & $1.98 \pm 0.04 \mathrm{efg}$ & $2.06 \pm 0.01 \mathrm{efg}$ & $1.94 \pm 0.04 \mathrm{fg}$ \\
C-Trim20 & $3.21 \pm 0.16 \mathrm{~d}$ & $3.57 \pm 0.03 \mathrm{c}$ & $3.33 \pm 0.01 \mathrm{~cd}$ \\
C-Trim30 & $5.78 \pm 0.29 \mathrm{~b}$ & $6.31 \pm 0.11 \mathrm{a}$ & $6.26 \pm 0.07 \mathrm{a}$ \\
C-Ttrim50 & $2.29 \pm 0.01 \mathrm{ef}$ & $2.33 \pm 0.01 \mathrm{e}$ & $2.07 \pm 0.06 \mathrm{efg}$ \\
$\beta$-Glucan95 & $1.11 \pm 0.02 \mathrm{~h}$ & $0.9 \pm 0.00 \mathrm{~h}$ & $0.84 \pm 0.00 \mathrm{~h}$ \\
\hline
\end{tabular}

Samples $(0.5 \mathrm{~g})$ were extracted with $10 \mathrm{ml}$ of corresponding solvents; Values are reported in $\mathrm{mg}$ gallic acid equivalents/g sample; Values with different letters indicate the significance $(p<0.05)$ for each comparison among all the treatments regardless solvent.

Table 4. Antioxidant activities of oat $\beta$-glucan hydrocolloids.

\begin{tabular}{cccc}
\hline & $\begin{array}{c}\text { Acetone }(80 \%) \\
\mu \mathrm{mol} / \mathrm{g}\end{array}$ & $\begin{array}{c}\text { Ethanol }(80 \%) \\
\mu \mathrm{mol} / \mathrm{g}\end{array}$ & $\begin{array}{c}\text { Methanol }(80 \%) \\
\mu \mathrm{mol} / \mathrm{g}\end{array}$ \\
\hline OBC & $1.97 \pm 0.00 \mathrm{~b}$ & $2.08 \pm 0.00 \mathrm{a}$ & $2.08 \pm 0.00 \mathrm{a}$ \\
Nutrim10 & $1.17 \pm 0.01 \mathrm{j}$ & $1.38 \pm 0.01 \mathrm{~g}$ & $1.46 \pm 0.01 \mathrm{f}$ \\
C-Trim20 & $1.30 \pm 0.00 \mathrm{~h}$ & $1.54 \pm 0.00 \mathrm{e}$ & $1.64 \pm 0.02 \mathrm{~d}$ \\
C-Trim30 & $1.83 \pm 0.00 \mathrm{c}$ & $1.86 \pm 0.00 \mathrm{c}$ & $1.95 \pm 0.01 \mathrm{~b}$ \\
C-Trim50 & $1.12 \pm 0.01 \mathrm{k}$ & $1.24 \pm 0.01 \mathrm{i}$ & $1.22 \pm 0.02 \mathrm{i}$ \\
$\beta$-Glucan95 & - & - & - \\
\hline
\end{tabular}

Samples $(0.5 \mathrm{~g})$ were extracted with $10 \mathrm{ml}$ of corresponding solvents; Values were reported in $\mu \mathrm{mol}$ Trolox equivalents/g sample; Values with different letters indicated the significance $(p<0.05)$ for each comparison among all the treatments regardless solvent; Values for $\beta$-Glucan95 were under detection limit.

ratio 1:20 was used for comparing the effect of solvent on phenolic contents according an earlier study [46]. Most likely, the lower phenolic values at the sample and solvent ratio of 1:20 (w/v) with $80 \%$ acetone, ethanol, and methanol could be caused by the low reactivity in the higher viscosity of the extraction slurry compared with ratio of 1:50. The result was in agreement with a previous study where the total flavonoid content in buckwheat was gradually increased to $1: 50$ ratio [37].

\subsection{Water-Holding Capacity}

Water-holding capacities of oat $\beta$-glucan hydrocolloids are shown in Figure 1. Water-holding capacities of CTrim30 and C-Trim50 were similar (1924\% and 1951\%) and both were significantly higher than other samples. $\beta$-Glucan95, which had the highest total highest $\beta$-glucan among the oat $\beta$-glucan hydrocolloids studied, had a lower water-holding capacity (1254\%) than C-Trim 30 and C-Trim50, suggesting that starch and fiber interaction could be an important factor. The $\beta$-glucan content 
Table 5. Comparison of the phenolic contents of oat $\beta$-glucan hydrocolloids using gallic acid and ferulic acid.

\begin{tabular}{ccccccc}
\hline & \multicolumn{2}{c}{ Acetone $(80 \%)$} & \multicolumn{2}{c}{ Ethanol (80\%) } & \multicolumn{2}{c}{ Methanol (80\%) } \\
\cline { 2 - 7 } & Gallic $\mathrm{mg} / \mathrm{g}$ & Ferulic $\mathrm{mg} / \mathrm{g}$ & Gallic $\mathrm{mg} / \mathrm{g}$ & Ferulic $\mathrm{mg} / \mathrm{g}$ & Gallic mg/g & Ferulic mg/g \\
\hline OBC & $2.29 \pm 0.09 \mathrm{a}$ & $1.98 \pm 0.10 \mathrm{a}$ & $2.25 \pm 0.03 \mathrm{a}$ & $1.93 \pm 0.03 \mathrm{~b}$ & $1.78 \pm 0.02 \mathrm{a}$ & $1.41 \pm 0.02 \mathrm{~b}$ \\
Nutrim10 & $1.98 \pm 0.04 \mathrm{a}$ & $1.66 \pm 0.05 \mathrm{~b}$ & $2.06 \pm 0.01 \mathrm{a}$ & $1.75 \pm 0.02 \mathrm{~b}$ & $1.94 \pm 0.04 \mathrm{a}$ & $1.61 \pm 0.05 \mathrm{~b}$ \\
C-Trim20 & $3.21 \pm 0.16 \mathrm{a}$ & $3.03 \pm 0.18 \mathrm{a}$ & $3.57 \pm 0.03 \mathrm{a}$ & $3.43 \pm 0.03 \mathrm{~b}$ & $3.33 \pm 0.01 \mathrm{a}$ & $3.16 \pm 0.02 \mathrm{~b}$ \\
C-Trim30 & $5.78 \pm 0.29 \mathrm{a}$ & $5.89 \pm 0.32 \mathrm{a}$ & $6.31 \pm 0.11 \mathrm{a}$ & $6.48 \pm 0.13 \mathrm{a}$ & $6.26 \pm 0.07 \mathrm{a}$ & $6.42 \pm 0.08 \mathrm{a}$ \\
C-Trim50 & $2.29 \pm 0.01 \mathrm{a}$ & $2.00 \pm 0.02 \mathrm{~b}$ & $2.33 \pm 0.01 \mathrm{a}$ & $2.04 \pm 0.02 \mathrm{~b}$ & $2.07 \pm 0.06 \mathrm{a}$ & $1.75 \pm 0.07 \mathrm{~b}$ \\
$\beta$-Glucan95 & $1.11 \pm 0.02 \mathrm{a}$ & $0.67 \pm 0.02 \mathrm{~b}$ & $0.90 \pm 0.00 \mathrm{a}$ & $0.45 \pm 0.01 \mathrm{~b}$ & $0.84 \pm 0.02 \mathrm{a}$ & $0.38 \pm 0.01 \mathrm{~b}$ \\
\hline
\end{tabular}

Samples $(0.5 \mathrm{~g})$ were extracted with $10 \mathrm{ml}$ of corresponding; Values are reported in $\mathrm{mg}$ gallic acid equivalents/g sample; Values with different letters indicate the significance $(p<0.05)$ between treatments using same solvent in the respective row.

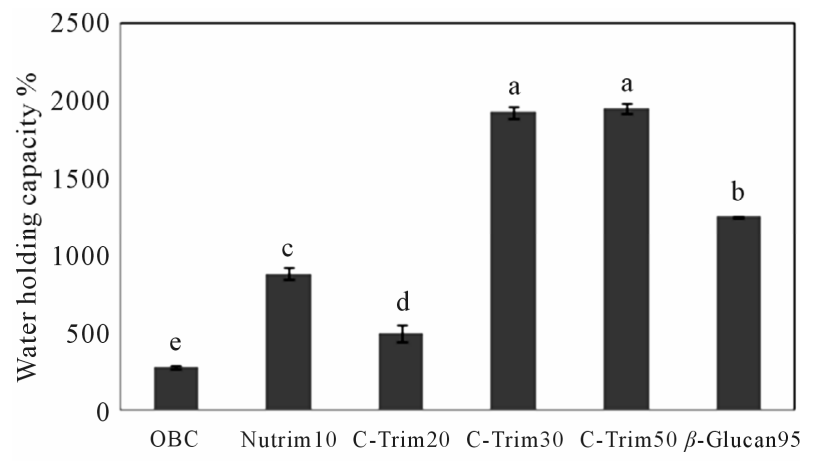

Figure 1. Water holding capacity of oat $\beta$-glucan hydrocolloids. The means for each variable with different letters are significantly different $(p \leq \mathbf{0 . 0 5})$.

of Nutrim 10 was only $4 \%$ higher than OBC but the water holding capacity of Nutrim10 (880\%) was almost three times of that from OBC $(277 \%)$. Since Nutrim10, CTrim20, C-Trim30, C-Trim50 were produced using jetcooking technology (Table 1), thermal mechanical shear forces could have resulted in their molecular breakdown [24]. Studies of water holding capacity provide fundamental information that helps explain RVA results.

\subsection{RVA Pasting Properties}

The pasting curves of oat $\beta$-glucan hydrocolloids were obtained by RVA analysis. As shown in Figure 2, the pasting curves of five oat $\beta$-glucan hydrocolloids were all different. $\beta$-Glucan95, C-Trim50, and C-Trim30 peak viscosity occurred almost instantaneously as exhibited with a rapid initial viscosity. It suggested that oat hydrocolloids could be quickly gelatinized during heating which is characteristic of pregelatinized flour [47]. In addition, the higher $\beta$-glucan content of $\beta$-Glucan95 could be a major contributor to a high paste viscosity. A continuous decline in the viscosity of $\beta$-Glucan95, C-Trim50 and $\mathrm{C}$-Trim30 was observed during heating after the initial peak, followed by an increase on cooling. It is known that the viscosity of completely gelatinized starch slurry decreases during heating due to the slurry thinning [48]. $\beta$-Glucan95 had considerably higher final viscosity (Figure 2), suggesting that $\beta$-glucan resulted in entanglement of molecules during cooling that formed a matrix with greater stability to heat and shear. A similar trend was observed for C-Trim50, as cooking resulted in a high final viscosity compared to other samples. Likewise, $\mathrm{OBC}$ and Nutrim 10 had lower paste viscosity than other samples probably due to the lower $\beta$-glucan content. No huge breakdowns (peak viscosity minus trough viscosity) were observed for oat $\beta$-glucan hydrocolloids, reflecting high stability under heat and shear. The steep and narrow peak viscosity curve was attributed to a complex formation between gelatinized starches and $\beta$-glucan in oats that was observed for jet-cooked oat bran concentrate [49].

Textural improvement in properties of foods using oat $\beta$-glucan hydrocolloids have been reported that the RVA data could provide useful information for food processing and product development. Initial paste viscosity suggested their suitability as ingredients for instant puddings and food formulations that require little heat during processing, such as, yogurt, smoothies and ice cream. For low paste viscosity of OBC and Nutrim10, they could be mixed with cereal flour, such as wheat flour, to make products such as breads and cookies for increasing their antioxidant activities.

\section{Conclusion}

Four oat $\beta$-glucan hydrocolloids and OBC revealed wide ranges of total phenolics and antioxidant activities resulting from the extraction conditions that were critical for obtaining high yields. In general, the highest solubilized phenolic compounds were found using high temperature up to $100^{\circ} \mathrm{C}$ for oat $\beta$-glucan hydrocolloids regardless of solvent but did not necessarily result in higher antioxidant activity. Water extracts had significantly higher phenolic contents than extracts using 50\% ethanol at $100^{\circ} \mathrm{C}$ for most samples. From these results, it is ap 


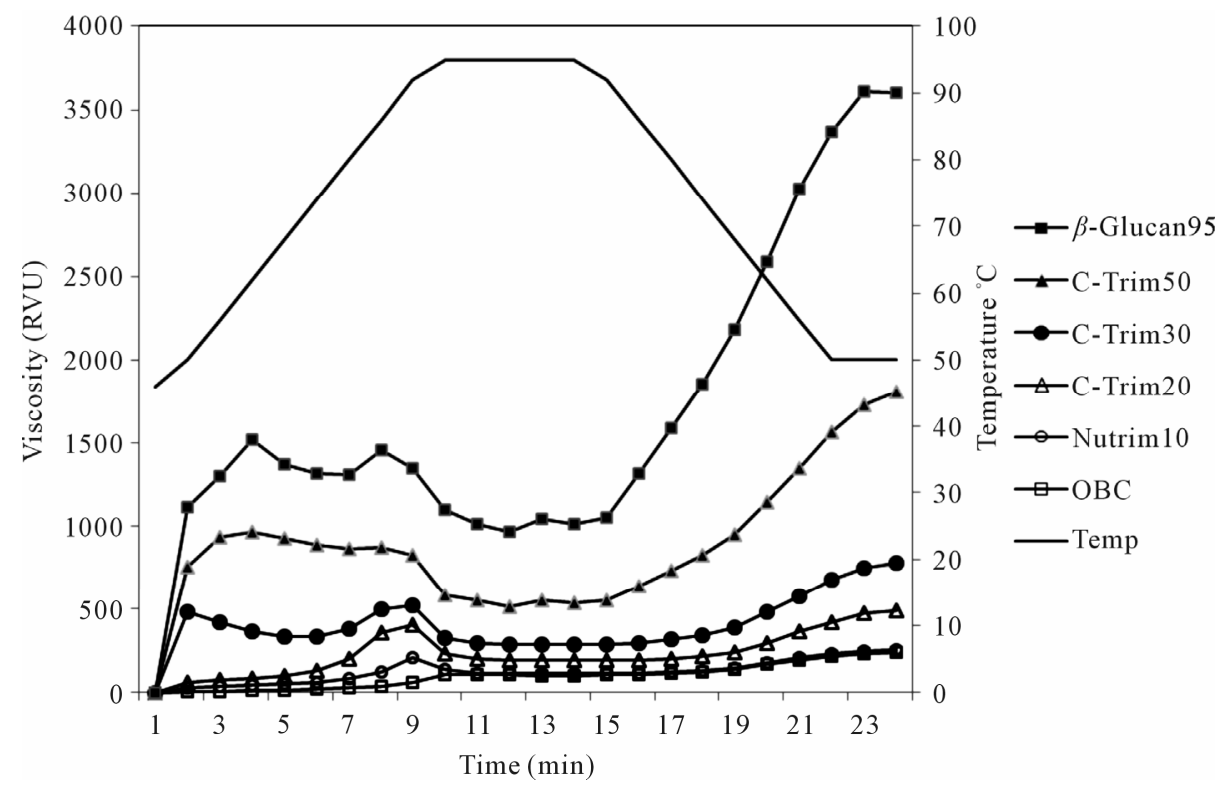

Figure 2. Rapid Visco-Analyser pasting curve of oat $\beta$-glucan hydrocolloids.

parent that oat $\beta$-glucan hydrocolloids and $\mathrm{OBC}$ could have great potential in providing nutritionally beneficial products based on their phenolic compounds and antioxidant capacity along with their unique water holding and paste viscosity. These oat $\beta$-glucan hydrocolloids, Nutrim10, C-Trim20 and C-Trim30, could provide excellent food ingredients for improving nutrition and modifying texture of healthy food products.

\section{REFERENCES}

[1] C.-Y. Chen, P. E. Milbury, H.-K. Kwak, F. W. Collins, P. Samuel and J. B. Blumberg, "Avenanthramides and Phenolic Acids from Oats Are Bioavailable and Act Synergistically with Vitamin $\mathrm{C}$ to Enhance Hamster and $\mathrm{Hu}$ man LDL Resistance to Oxidation," Journal of Nutrition, Vol. 134, No. 6, 2004, pp. 1459-1466.

[2] A. Berg, D. König, P. Deibert, D. Grathwohl, A. Berg, M. W. Baumstark and I. W. Franz, "Effect of an Oat Bran Enriched Diet on the Atherogenic Lipid Profile in Patients with an Increased Coronary Heart Disease Risk," Annals of Nutrition and Metabolism, Vol. 47, No. 6, 2003, pp. 306-311. doi:10.1159/000072404

[3] N. Tapola, H. Karvonen, L. Niskanen, M. Mikola and E. Sarkkinen, "Glycemic Responses of Oat Bran Products in Type 2 Diabetic Patients," Nutrition, Metabolism \& Cardiovascular Diseases, Vol. 15, No. 4, 2005, pp. 255-261. doi:10.1016/j.numecd.2004.09.003

[4] J. He, R. H. Streiffer, P. Muntner, M. A. Krousel-Wood, and P. K. Whelton, "Effect of Dietary Fiber Intake on Blood Pressure: A Randomized, Double-Blind, PlaceboControlled Trial," Journal of Hypertension, Vol. 22, No. 1, 2004, pp. 73-80. doi:10.1097/00004872-200401000-00015

[5] K. K. A. Adom and R. H. Liu, "Antioxidant Activity of
Grains," Journal of Agriculture and Food Chemistry, Vol. 50, No. 21, 2002, pp. 6182-6187. doi:10.1021/jf0205099

[6] Z. Zduńczyk, M. Flis, H. Zieliński, M. Wróblewska, Z. Antoszkiewicz and J. Juśkiewicz, "In Vitro Antioxidant Activities of Barley, Husked Oat, Naked Oat, Triticale, and Buckwheat Wastes and Their Influence on the Growth and Biomarkers of Antioxidant Status in Rats," Journal of Agricultural and Food Chemistry, Vol. 54, 2006, pp. 4168-4175. doi:10.1021/jf060224m

[7] T. Madhujith and F. Shahidi, "Antioxidative and Antiproliferative Properties of Selected Barley (Hordeum vulgare L.) Cultivars and Their Potential for Inhibition of Low-Density Lipoprotein (LDL) Cholesterol Oxidation," Journal of Agricutlural and Food Chemistry, Vol. 55, 2007, pp. 5018-5024. doi:10.1021/jf070072a

[8] G. E. Inglett, "Soluble Hydrocolloid Food Additives and Method of Making," US Patent 6060519, 2000.

[9] C. F. Klopfenstein, "The Role of Cereal Beta-Glucans in Nutrition and Health," Cereal Food Worlds, Vol. 33, 1988, pp. 865-869.

[10] D. M. Peterson, C. L. Emmons and A. H. Hibbs, "Phenolic Antioxidants and Antioxidant Activity in Pearling Fractions of Oat Groats," Journal of Cereal Science, Vol. 33, No. 1, 2001, pp. 97-103. doi:10.1006/jcrs.2000.0347

[11] L. Liu, L. Zubik, F. W. Collins, M. Marko and M. Meydani, "The Antiatherogenic Potential of Oat Phenolic Compounds," Atherosclerosis, Vol. 175, No. 1, 2004, pp. 39-49. doi:10.1016/j.atherosclerosis.2004.01.044

[12] S. Sayar, J.-L. Jannink and P. J. White, "In Vitro Bile Acid Binding Activity within Flour Fractions from Oat Lines with Typical and High $\beta$-Glucan Amounts," Journal of Agricultural and Food Chemistry, Vol. 54, 2006, pp. 5142-5148. doi:10.1021/jf060384y

[13] D. G. Stevenson, G. E. Inglett, D. Chen, A. Biswas, F. J. Eller and R. L. Evangelista, "Phenolic Content and Anti- 
oxidant Capacity of Supercritical Carbon Dioxide-Treated and Air-Classified Oat Bran Concentrate Microwave-Irradiated in Water or Ethanol at Varying Temperatures," Food Chemistry, Vol. 108 , 2008, pp. 23-30. doi:10.1016/j.foodchem.2007.08.060

[14] L. Brindzová, M. Mikulášová, M. Takácsová, S. Mošovská and A. Opattová, "Evaluation of the Mutagenicity and Antimutagenicity of Extracts from Oat, Buckwheat and Wheat Bran in the Salmonella/Microsome Assay," Journal of Food Composition and Analysis, Vol. 22, No. 1, 2009, pp. 87-90. doi:10.1016/j.jfca.2008.07.009

[15] R. H. Auerbach and D. A. Gray, "Oat Antioxidant Extraction and Measurement-Towards a Commercial Process," Journal of the Science of Food and Agriculture, Vol. 79, 1999, pp. 385-389. doi:10.1002/(SICI)1097-0010(19990301)79:3<385::AIDJSFA260>3.0.CO;2-L

[16] K. J. Duve and P. J. White, "Extraction and Identification of Antioxidants in Oats," Journal of the American Oil Chemist's Society, Vol. 68, No. 6, 1991, pp. 365-370. doi:10.1007/BF02663751

[17] K. Zhou and L. Yu, "Effects of Extraction Solvent on Wheat Bran Antioxidant Activity Estimation," Lebensmittel-Wissenschaft und-Technologie, Vol. 37, 2004, pp. 717-721.

[18] H. Zieliński and H. Kozłowska, "Antioxidant Activity and Total Phenolics in Selected Cereal Grains and Their Different Morphological Fractions," Journal of Agricultural and Food Chemistry, Vol. 48, No. 6, 2000, pp. 2008-2016. doi:10.1021/if990619o

[19] M. Bonoli, V. Verardo, E. Marconi and M. F. Caboni, "Antioxidant Phenols in Barley (Hordeum vulagare L.) Flour: Comparative Spectrophotometric Study among Extraction Methods of Free and Bound Phenolic Compounds," Journal of Agricultural and Food Chemistry, Vol. 52, 2004, pp. 5195-5200. doi:10.1021/jf040075c

[20] T. Madhujith, M. Izydorczyk and F. Shahidi, "Antioxidant Properties of Pearled Barley Fractions," Journal of Agricultural and Food Chemistry, Vol. 54, 2006, pp. 3283-3289. doi:10.1021/jf0527504

[21] S. Maneepun, T. Boonpunt and G. E. Inglett, "Sensory and Nutritional Evaluation of Co-Processed Nutrim OB and Soy Flour in Thai Dishes," 216th ACS National Meeting, AGFD-099, Boston, 1998, p. 31.

[22] K. Warner and G. E. Inglett, "Flavor and Texture Characteristics of Foods Containing Nutrim Oat Bran Hydrocolloid," 216th ACS National Meeting, AGFD-97, Boston, 1998, p. 31.

[23] S. Lee, G. E. Inglett and C. J. Carriere, "Effect of Nutrim Oat Bran and Flaxseed on Rheological Properties of Cakes," Cereal Chemistry, Vol. 81, No. 5, 2004, pp. 637-642. doi:10.1094/CCHEM.2004.81.5.637

[24] S. Lee and G. E. Inglett, "Rheological and Physical Evaluation of Jet-Cooked Oat Bran in Low Calorie Cookies," International Journal of Food Science and Technology, Vol. 41, No. 5, 2006, pp. 553-559. doi:10.1111/j.1365-2621.2005.01105.x

[25] S. Kim, G. E. Inglett and S. X. Liu, "Content and Mo- lecular Weight Distribution of Oat $\beta$-Glucan in Oatrim, Nutrim, and C-Trim Products," Cereal Chemistry, Vol. 85 , No. 5, 2008, pp. 701-705. doi:10.1094/CCHEM-85-5-0701

[26] P. S. Thondre, L. Ryan and C. J. K. Henry, "Barley $\beta$-Glucan Extracts as Rich Sources of Polyphenols and Antioxidants," Food Chemistry, Vol. 126, No. 1, 2011, pp. 72-77. doi:10.1016/i.foodchem.2010.10.074

[27] P. Sharma and H. S. Gujral, "Antioxidant and Polyphenol Oxidase Activity of Germinated Barley and Its Milling Fractions," Food Chemistry, Vol. 120, 2010, pp. 673-678. doi:10.1016/j.foodchem.2009.10.059

[28] A. L. Waterhouse, "Determination of Total Phenolics," In: R. E. Wrolstad, Ed., Current Protocols in Food Analytical Chemistry, John Wiley \& Sons, New York, 2001, pp I.1.1.1-I.1.1.8.

[29] L. Yu and K. Zhou, "Antioxidant Properties of Bran Extracts from Platte Wheat Grown at Different Locations," Food Chemistry, Vol. 90, 2004, pp. 311-316. doi:10.1016/i.foodchem.2004.04.007

[30] I. Sensoy, R. T. Rosen, C.-T. Ho and M. V. Karwe, "Effect of Processing on Buckwheat Phenolics and Antioxidant Activity," Food Chemistry, Vol. 99, No. 2, 2006, pp. 388-393. doi:10.1016/j.foodchem.2005.08.007

[31] B. I. O. Ade-Omowaye, K. A. Taiwo, N. M. Eshtiaghi, A. Angersbach and D. Knorr, "Comparative Evaluation of the Effects of Pulsed Electric Field and Freezing on Cell Membrane Permeabilisation and Mass Transfer during Dehydration of Red Bell Peppers," Innovative Food Science and Emerging Technologies, Vol. 4, 2003, pp. 177188. doi:10.1016/S1466-8564(03)00020-1

[32] SAS Institute Inc., "The SAS ${ }^{\circledR}$ System for Windows ${ }^{\circledR}$," Version 8e, Cary, 1999.

[33] A. Siger, M. Nogala-Kalucka and E. Lampart-Szczapa, "The Content and Antioxidant Activity of Phenolic Compounds in Cold-Pressed Plant Oils," Journal of Food Lipids, Vol. 15, No. 2, 2008, pp. 137-149. doi:10.1111/j.1745-4522.2007.00107.x

[34] V. Gökmen, A. Serpen and V. Fogliano, "Direct Measurement of the Total Antioxidant Activity of Foods: The 'QUENCHER' Approach," Trends in Food Science and Technology, Vol. 20, No. 6-7, 2009, pp. 278-288.

[35] Y. Xing and P. J. White, "Identification and Function of Antioxidants from Oat Groats and Hulls," Journal of the American Oil Chemist's Society, Vol. 74, 1997, pp. 303307. doi:10.1007/s11746-997-0141-x

[36] S. Bryngelsson, L. H. Dimberg and A. Kamal-Eldin, "Effects of Commercial Processing on Levels of Antioxidants in Oats (Avena sativa L.)," Journal of Agricultural and Food Chemistry, Vol. 3, No. 50, 2002, pp. 18901896. doi: $10.1021 / \mathrm{jf0} 011222 \mathrm{z}$

[37] G. E. Inglett, D. Chen, M. Berhow and S. Lee, "Antioxidant Activity of Commercial Buckwheat Flours and Their Free and Bound Phenolic Composition," Food Chemistry, Vol. 125, 2010, pp. 923-929. doi:10.1016/j.foodchem.2010.09.076

[38] A. Liazid, M. Palma, J. Brigui and C. G. Barroso, "Investigation on Phenolic Compounds Stability during Micro- 
wave-Assisted Extraction," Journal of Chromatography $A$, Vol. 1140, No. 1-2, 2007, pp. 29-34.

[39] D. P. Makris and J. T. Rossiter, "Heat-Induced, MetalCatalyzed Oxidative Degradation of Quercetin and Rutin (Quercetin 3-O-Rhamnosylglucoside) in Aqueous Model Systems," Journal of Agricultural and Food Chemistry, Vol. 48, No. 9, 2000, pp. 3830-3838. doi:10.1021/jf0001280

[40] M. Watanabe, Y. Ohshita and T. Tsushida, "Antioxidant Compounds from Buckwheat (Fagopyrum esculentum Möench) Hulls," Journal of Agricultural and Food Chemistry, Vol. 45, 1991, pp. 1039-1044. doi:10.1021/jf9605557

[41] G. E. Inglett, D. J. Rose, D. G. Stevenson, D. Chen and A. Biswas, "Total Phenolics and Antioxidant Activity of Water and Ethanolic Extracts from Distillers Dried Grains with Soluble with or without Microwave Irradiation," Cereal Chemistry, Vol. 86, 2009, pp. 661-664. doi:10.1094/CCHEM-86-6-0661

[42] T. Sun and C. T. Ho, "Antioxidant Activities of Buckwheat Extracts," Food Chemistry, Vol. 90, No. 4, 2005, pp. 743-749. doi:10.1016/j.foodchem.2004.04.035

[43] S. Guyot, N. Marnet, D. Laraba, P. Sanoner and J.-F. Drilleau, "Reversed-Phase HPLC Following Thiolysis for Quantitative Estimation and Characterization of the Four Main Classes of Phenolic Compounds in Different Tissue Zones of a French Cider Apple Variety (Malus domestica var. Kermerrien)," Journal of Agricultural and Food Chemistry, Vol. 46, No. 5, 1998, pp. 1698-1705. doi:10.1021/jf970832p

[44] P. Jankovska, J. Copikova, A. Sinitsya and M. Novotna, "The Effect of Ferulic Acid on the Structure of Plant Cell
Wall and Its Determination," Czech Journal of Food Science, Vol. 18, 2000, pp. 182-183.

[45] H. D. Shin, S. McClendon, T. Le, F. Taylor and R. R. Chen, "A Complete Enzymatic Recovery of Ferulic Acid from Corn Residues with Extracellular Enzymes from Neosartorya Spinosa NRRL185," Biotechnology and Bioengineering, Vol. 95, No. 6, 2006, pp. 1108-1115. doi:10.1002/bit.21056

[46] H. Zhao, J. Dong, J. Lu, J. Chen, Y. Li, L. Shan, Y. Lin, W. Fan and G. Gu, "Effects of Extraction Solvent Mixtures on Antioxidant Activity Evaluation and Their Extraction Capacity and Selectivity for Free Phenolic Compounds in Barley (Hordeum vulgare L.)," Journal of Agricultural and Food Chemistry, Vol. 54, No. 19, 2006, pp. 7277-7286. doi:10.1021/jf061087w

[47] H.-M. Lai and H.-H. Cheng, "Properties of Pregelatinized Rice Flour Made by Hot Air or Gum Puffing," International Journal of Food Science and Technology, Vol. 39, No. 2, 2004, pp. 201-212. doi:10.1046/j.0950-5423.2003.00761.x

[48] M. Guha, S. Zakiuddin and S. Bhattacharya, "Effect of Barrel Temperature and Screw Speed on Rapid Viscoanalyser Pasting Behavior of Rice Extrudate," International Journal of Food Science \& Technology, Vol. 33, 1998 , pp. 259-266. doi:10.1046/j.1365-2621.1998.00189.x

[49] D. G. Stevenson, F. J. Eller, M. Radosavljević, J. Jane and G. E. Inglett, "Characterisation of Oat Bran Products with and without Supercritical Carbon Dioxide Extraction," International Journal of Food Science \& Technology, Vol. 42, No. 12, 2007, pp. 1489-1496. doi:10.1111/j.1365-2621.2006.01370.x 